\title{
Using Grounded Theory Approach for Exploring Factors Affecting the Ineffectiveness of Positive Word-of-Mouth
}

\author{
Feng $\mathrm{JI}^{1, \mathrm{a}^{*}}$ Fan $\mathrm{WU}^{2, \mathrm{~b}}$ Han Bing SHEN ${ }^{3, \mathrm{c}}$ \\ ${ }^{1,2,3}$ School of Management, China University of Mining \& Technology, Xuzhou, China ,221116 \\ accumtjifeng@cumt.edu.cn, b455650874@qq.com, cshbcumt@126.com
}

Keywords: Positive word of mouth; Grounded theory approach; Word-of-mouth ineffectiveness

\begin{abstract}
Nowadays, ineffectiveness of positive word-of-mouth is common, challenging companies' word of mouth marketing. Based on grounded theory, the paper conducted repeated studies by 55 respondents' information. This research proposed driving mechanism model of the ineffectiveness factors of positive word-of-mouth, then tested the saturation level of this mechanism. The results show that the relationship between senders and receivers, message factor, initial expectation, expectation gap, situational factor, psychological resistance have indirect impact on ineffectiveness of positive word-of-mouth. Moreover, message factor and consumer expectation have indirect impact on ineffectiveness of positive word-of-mouth that through psychological resistance, which formed the "message factor/expectation - psychological resistance -positive word of mouth ineffectiveness" driving relationship; the relationship between senders and receivers and situational factor play a regulatory role, which regulated the extent and intensity of "message factor - psychological resistance" and "psychological resistance -positive word of mouth ineffectiveness" relations.
\end{abstract}

\section{Introduction}

Word of mouth (WOM)is informal spread of the product feature, purchase, use, and the seller for other consumers (Westbrook, 1987).It can be divided into offline word of mouth and online word of mouth (Yu and Wang, 2013).Word of mouth communication has been very popular, with high persuasive and high-impact. According to Froster's prediction, sales will be affected by electronic word of mouth more than $50 \%$ in 2014(Froster, 2012). It is because of word of mouth plays such an important role, currently many domestic and foreign enterprises have begun to actively trying various levels of "word of mouth marketing." Compared with positive and negative information, some studies show the negative word of mouth has larger impact on consumer than the positive word of mouth. But, the impact of positive word of mouth can not be ignored. Many studies have confirmed that positive word of mouth can strengthen consumer expectations and promote consumers to buy (e.g., Chevalier and Mayzlin, 2006; Liu, 2006).

However, the effective role of positive word of mouth in consumer buying behavior has not yet reached 100\%.Many scholars have confirmed this opinion by empirical research. The research on the relationship between word of mouth and new product adoption behavior found that the proportion accounted for $46 \%$ that receiving positive word of mouth does not buy (Arndt, 1967).In addition, the study found $18 \%$ of consumers are not affected by the reviews(Sen, Shahana et 
al.,2008). In the same year, there is study found the proportion of positive word of mouth can not influence decisions were $67 \%$ of supermarkets, $44 \%$ of bank accounts, $14 \%$ of restaurant (East et al., 2008). All these things are the ineffectiveness of positive word of mouth, which led to the opposite effect. So far, there is relatively little research about factors affecting the ineffectiveness of positive word of mouth.

\section{Literature review}

Some scholars from word of mouth source characteristics, the homogeneity between the receiver and sender and the receiver features three aspects to explore effect of word of mouth for consumers, involved in the regulation of product category, the research results show that the receiver's professional perception of word-of-mouth source has an important positive influence on opinion leaders and consumer's decision-making process; in the case of durable goods, the receiver's professional knowledge has a negative impact on word of mouth preferences and consumer word-of-mouth behavior; perceived homogeneity has a positive influence on consumer decision-making process(Gilly et al.,1998). Perceived homogeneity' positive impact on consumer behavior has also been verified by other scholars(Feldman and Spencer, 1965; Brown and Reingen, 1987). If not credible information source, and the differences with the receiver, namely the psychological distance is far, consumers will think the spread of information has little value for their reference, and thus there will be resistance to information, so these factors may lead to ineffectiveness of word of mouth.

The strength of relationship between the behavior main bodies will affect the receiver's judgment and cognition of information. The strength of the information itself and the consistency of the transmission will also affect the receiver's perception of the value of information. Moreover, if the information itself is more vivid and can attract the attention of the receiver, the effect of spread may be better, so these factors may also lead to word of mouth ineffectiveness. Some of the domestic and foreign scholars have confirmed this view. For instance, studies have found that the strength of social ties affects consumer behavior, and influence degree is different in different decision phase (De Bruyn and Lilien, 2008).

As consumers behavior of active information search can enhance word of mouth effect and increase the impact on the consumer purchase decision, in turn, may also be affecting factors of ineffectiveness of word of mouth. William C. Martin and Jason E. Lueg (2013) explored regulating effect that purchase involvement, self-awareness, and word of mouth forms regulating the relation between credible source, source of experience, expertise and evidence and the effectiveness of word of mouth.

In addition, some previous studies have shown that word-of-mouth is actually cultural orientation, including the content, process and communication situation. As a result, the spread of cross-cultural and cross region should pay attention to products and services to the target object characteristics, transmission scenario and the compatibility of both sides of the cultural background and values(Huang Xiaojun,2004), thus conducting an effective communication.

Overall, the scholars' studies on the influence factors of word-of-mouth effect have been relatively mature. Some of the factors above all are the key factors to promote the effective spread of word-of-mouth. Past research has shown that positive and negative affecting factors may exist asymmetric phenomenon (LaBarbera and Mazursky,1983), therefore, affecting factors of ineffectiveness is derived directly from positive word of mouth effective factors is not reasonable. 
Moreover, the current study shows that despite the positive word of mouth are a common failure, but the affecting factors led to the failure and the mechanism between them do not have a convincing answer. Therefore, this paper uses grounded theory approach to explore the affecting factors of ineffectiveness of positive word of mouth and its transmission mechanism.

\section{Research methodology}

Grounded theory overview. Grounded theory approach was proposed by two American sociologists Glaser and Strauss in 1967.It has high influence in processing with qualitative data, and is a bottom-up inductive and deductive core concepts from phenomena or empirical data, thereby gradually create and improve relevant substantive theory(Glaser, Strauss,1967). Primary research process of Grounded theory approach shows in Figure 1.

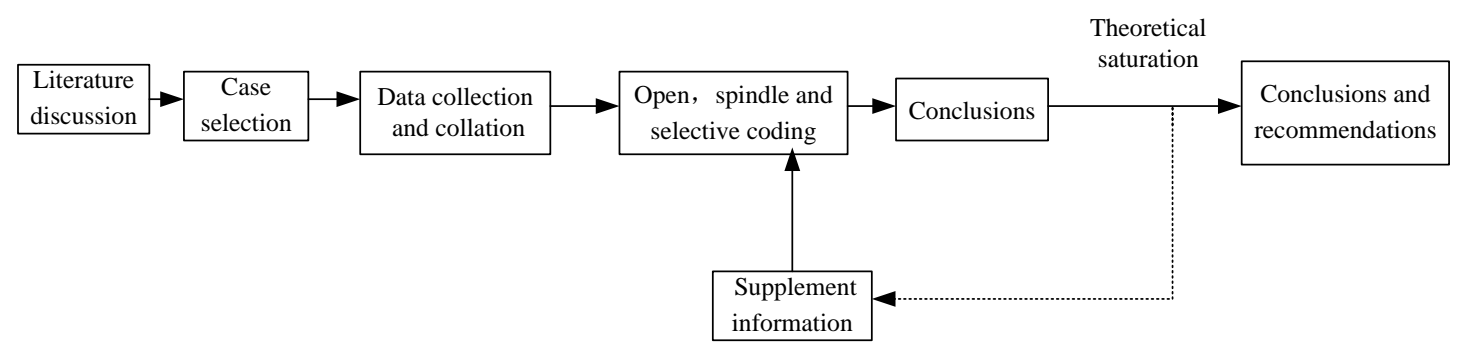

Fig.1 Flowchart of grounded theory research

Since the concept, category, measurement scale and the theoretical model of the affecting factors of ineffectiveness of positive word of mouth is no comprehensive conclusion; it may not be effective to conduct large sample survey by designing a structured questionnaire. Moreover, it needs extensive source of information to explore these factors, because ineffectiveness of positive word of mouth is affected by many factors. Considering the grounded theory approach is to explore the core concepts behind the phenomenon from the original data, analysis and code repeatedly data to detect certain concepts, categories and its intrinsic link, and ultimately build a theoretical model rooted in the practice, therefore, the use of Grounded theory approach is scientific and reasonable to research affecting factors of ineffectiveness positive word of mouth.

Data collection. Personal depth interviews and focus group interviews are commonly used in data collection methods in the qualitative research process. This paper selects 55 students both undergraduate and graduate students from China University of Mining and Technology University to conduct interviews, who have common experiences that are accepted in the past three months had a positive word of mouth, but did not make the final purchase decision, of which 20 interview subjects for testing theoretical saturation. The above approach is the use of grounded theory mainly mature experience, in order to ensure sample saturation theory. During this period, with the three coding steps of grounded theory, we carried out 55 times, respectively, the individual in-depth interviews, each interview lasted more than 30 minutes, and organized six focus group interviews, participants in each 7-10 people, each interview time was 60 minutes.

\section{Extracting concepts, category and building model}

After the interviews, the researchers sorted out verbatim in detail in accordance with the contents of recordings and notes, in addition to interviews with the expletive deleted, all other information is accurately transcribed. Coding of grounded theory includes open coding, axial coding and selective 
coding, according to the selective coding to build model, ultimately it comes to affecting factors of ineffectiveness of positive word of mouth and mechanism model.

Open coding. Open coding is the process of conceptualization and categorization to the original data. This paper adopted the open coding procedures as follows: conceptualization-mining areas-to determine the name of category-to determine nature of the category, which was proposed by Yan Jun and She Qiuling in 2010(Yan and She,2010). In the process of conceptualization, the raw data was collated and analyzed as the initial concept, which had obtained 174 initial concepts. After deleting the occurrence frequency of the initial concept less than 3 times, eventually it had 155 initial concepts. Then, In the process of categorization, the initial concepts that have the same or similar connotation will be classified as a category; eventually it got 11 categories, as shown in Table 1 . Table 1 lists only 11 categories and former three initial concepts that have higher occurrence frequency.

Table 1 The initial concept and category of open coding generated

\begin{tabular}{|c|c|c|c|}
\hline No. & Definition & Category & The initial concept (occurrence frequency) \\
\hline 1 & $\begin{array}{l}\text { Similarity between the senders and } \\
\text { receivers }\end{array}$ & Similarity & $\begin{array}{l}\text { Differences in preferences(27), Inconsistent values(22), } \\
\text { Large gap in life(13) }\end{array}$ \\
\hline 2 & $\begin{array}{l}\text { Close degree of relationship between } \\
\text { the senders and receivers }\end{array}$ & $\begin{array}{l}\text { The strength of } \\
\text { relationship }\end{array}$ & $\begin{array}{l}\text { Stranger(25), Relationship is not very good(11), Not } \\
\text { know much about him/her(10) }\end{array}$ \\
\hline 3 & $\begin{array}{l}\text { Small amount of positive word of } \\
\text { mouth information contained passed }\end{array}$ & $\begin{array}{l}\text { Low information } \\
\text { content of word of } \\
\text { mouth }\end{array}$ & $\begin{array}{l}\text { Monotonous(26),Small amount of information(19), } \\
\text { Unattractive(17) }\end{array}$ \\
\hline 4 & of information & $\begin{array}{l}\text { Inconsistent word of } \\
\text { mouth }\end{array}$ & $\begin{array}{l}\text { Opposing voices(21), Negative reviews(15), Bad } \\
\text { message(10) }\end{array}$ \\
\hline 5 & Availability of products / services & Availability & $\begin{array}{l}\text { Not chance to try(15), No time( } 8) \text {, Place of purchase } \\
\text { constraints }(6)\end{array}$ \\
\hline 6 & $\begin{array}{l}\text { The urgency of purchasing products / } \\
\text { services }\end{array}$ & Demand urgency & $\begin{array}{l}\text { Do not need(14), Not ability to meet or possess(7), Not } \\
\text { necessary(5) }\end{array}$ \\
\hline 7 & $\begin{array}{l}\text { Consumer expectations arising after } \\
\text { the initial acceptance of positive word } \\
\text { of mouth }\end{array}$ & Initial expectations & $\begin{array}{l}\text { Initial feeling } \operatorname{good}(16) \text {, High expectations(9), Feel very } \\
\operatorname{good}(5)\end{array}$ \\
\hline 8 & $\begin{array}{l}\text { Gap after learning more about the } \\
\text { product }\end{array}$ & Expectations gap & $\begin{array}{l}\text { Not as good as imagination(19), Disappointed(11), Feel } \\
\text { cheated }(8)\end{array}$ \\
\hline 9 & $\begin{array}{l}\text { The receivers suspicion to the spread } \\
\text { of the positive word of mouth }\end{array}$ & Suspicion & $\begin{array}{l}\text { May exaggerate the benefits(19), Trusted?(15), Really so } \\
\text { good?(11) }\end{array}$ \\
\hline 10 & $\begin{array}{l}\text { The receivers resistance to the spread } \\
\text { of the positive word of mouth }\end{array}$ & Resistance & $\begin{array}{l}\text { Impure motivations(24), Deliberately arranged by } \\
\text { company(21), Advertising(11) }\end{array}$ \\
\hline 11 & $\begin{array}{l}\text { The spread of positive word of mouth } \\
\text { did not achieve the desired effect }\end{array}$ & $\begin{array}{l}\text { The ineffectiveness of } \\
\text { positive word of mouth }\end{array}$ & $\begin{array}{l}\text { Not promoting the purchase(31), Not affecting me(16), } \\
\text { Not further wishes to spread(11) }\end{array}$ \\
\hline
\end{tabular}

Axial coding. Axial coding is based on the initial concept and scope of open coding obtained, through the intrinsic link between categories to develop main categories, thereby forming a dimension of greater generic. This study compares and extracts the logical relationship among 12 categories based on table 1 through the way as follows: the causal conditions $\rightarrow$ thread of thought $\rightarrow$ intermediary conditions $\rightarrow$ action / interaction strategies $\rightarrow$ Result, such as table 2 . 
Table 2 The relationship based on axial coding emerged

\begin{tabular}{|c|c|c|}
\hline No. & Relationship category & Categories affected relationship \\
\hline 1 & Initial expectations & Initial expectations \\
\hline 2 & Expectations gap & Expectations gap \\
\hline 3 & Information feature & Low information content of word of mouth \\
\hline 4 & Relationship factors & $\begin{array}{l}\text { Inconsistent word of mouth } \\
\text { Similarity }\end{array}$ \\
\hline 5 & Situational factors & $\begin{array}{l}\text { The strength of relationship } \\
\text { Availability }\end{array}$ \\
\hline 6 & Resistance & $\begin{array}{l}\text { Demand urgency } \\
\text { Suspicion } \\
\text { Resistance }\end{array}$ \\
\hline 7 & The ineffectiveness of positive word of mouth & Not promoting the purchase/ not further wishes to spread \\
\hline
\end{tabular}

Selective coding and building model. Selective coding is to further explore "core category" in the main category, and link core category and other main category, and then through the "story" present overall coherent context of the study and the causal relation, and finally construct a new model. After selective coding, it has drawn a core category that is "affecting factors of ineffectiveness of positive word of mouth". A summary of the story around the core category will be described as follows: the relationship between senders and receivers, message factor, initial expectation, expectation gap, situational factor, psychological resistance has indirect impact on ineffectiveness of positive word-of-mouth. Moreover, message factor and consumer expectation have indirect impact on ineffectiveness of positive word-of-mouth that through psychological resistance, which formed the "message factor/expectation - psychological resistance -positive word of mouth ineffectiveness" driving relationship; the relationship between senders and receivers and situational factor play a regulatory role, which regulated the extent and intensity of "message factor - psychological resistance" and "psychological resistance -positive word of mouth ineffectiveness" relations. Based on the above story summary, we build a mechanism model of ineffectiveness of positive word of mouth, shown in Figure 2.

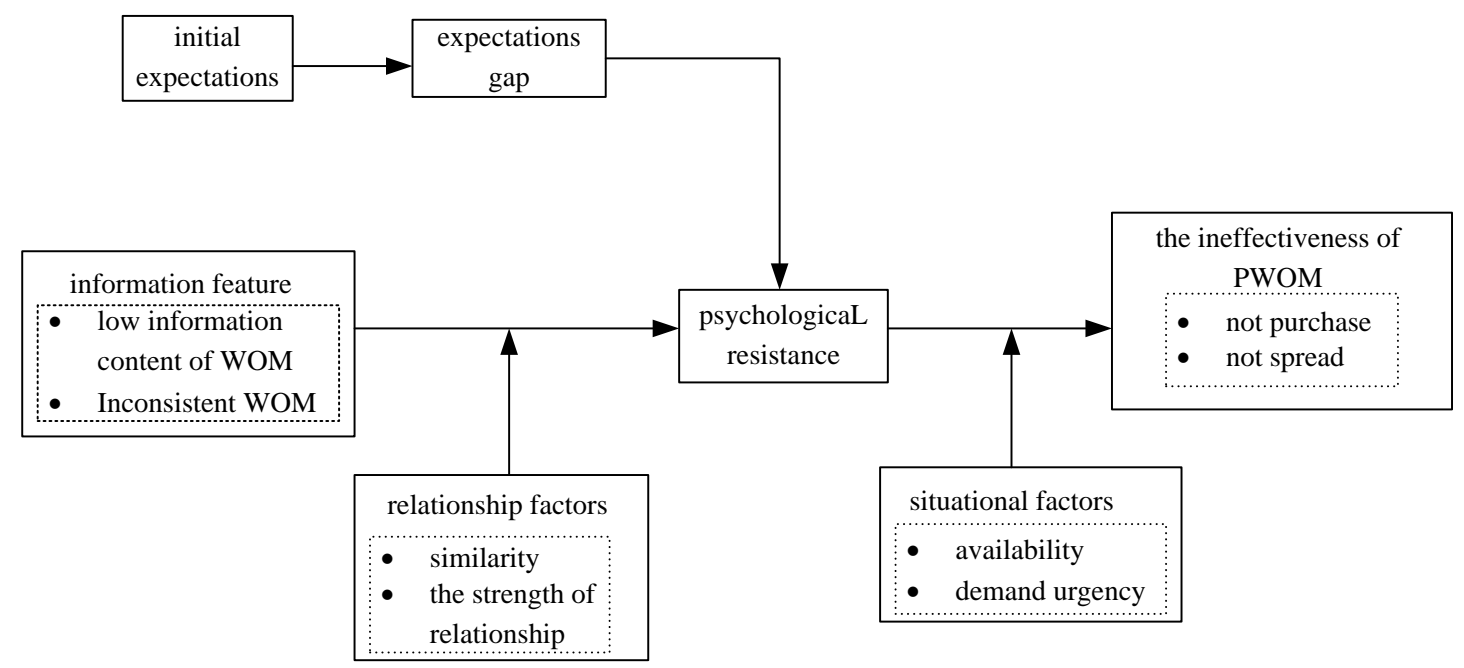

Fig. 2 Mechanism model of ineffectiveness of positive word of mouth

Theoretical saturation test. In this paper, the remaining 20 samples was tested theoretical saturation. To begin with, the study conducted one to one in-depth interviews, and then conducted a focus group interviews. According to three coding of Grounded theory approaches, the results are still in line with the model presented in context and relationships, but also through interviews, did not find a new initial concepts and categories, which determine the theoretical saturation has been 
reached, and the model of ineffectiveness of WOM is reasonable.

\section{Interpretation of model of "message factor/expectation - psychological resistance -positive word of mouth ineffectiveness"}

The model of "message factor/expectation-psychological resistance -positive word of mouth ineffectiveness" can be used to explain the formation mechanism of ineffectiveness of positive word of mouth. The affecting factors of ineffectiveness of positive word of mouth include the relationship between senders and receivers, message factor, initial expectation, expectation gap, situational factor, psychological resistance, but there are differences in the mechanism to the effectiveness of positive word of mouth.

"Message factor/expectation - psychological resistance" driving mechanism. On the one hand, consumers will produce different attitudes and awareness to the information received, due to the different information characteristics. Sometimes even the spread of information is very vivid, as consumers have suspicion of the content, thus arising from the heart to resist. Moreover, low information content of WOM because of lacking of persuasiveness, thereby causing consumer resistance. Additionally, when someone contacts positive word of mouth, and suddenly there are dissenting voices will bring to resist. In conclusion, information content of WOM and the consistency of WOM will affect consumer acceptance emotion, and then affect consumers' purchasing decisions.

On the other hand, due to the spread of positive word of mouth, the initial expectations of the consumer will improve. After the consumer familiarity with the product / service to a certain extent, arising some differences with the initial expectations, consumers will have a psychological gap, thus prone to psychological resistance.

"Psychological resistance -positive word of mouth ineffectiveness". As usage behavior of product/service is caused by a willingness to participate, and the willingness to participate is decided by personal attitudes on behavior, consequently, consumer acceptance of the attitude of word of mouth will directly affect the effect of positive word of mouth (Davis,1989). Under normal circumstances, consumers will have a positive evaluation of company's products or services, when consumers have the more active performance and more interested in the contents of word of mouth, resulting in greater likelihood of purchasing. On the contrary, if consumers hold a skeptical or psychological resistant to treatment communicators passing information, then the likelihood of consumers' purchase intention will be very small, so as to be positive word of mouth ineffective.

Mechanism of regulation factors on the "word of mouth - psychological resistance" and "psychological resistance - positive word of mouth ineffectiveness" relationship. The relationship between the senders and receivers has an important impact on the accepted emotion. In the close and similar relation situations, consumer has more confident to communicators, and then will be a better acceptance effect of positive word of mouth. On the contrary, if the relationship between the senders and receivers is not very close, the receivers may have suspicious about the spread information, thus may not achieve the desired effect. Meanwhile, the similarity will have a significant impact on consumer awareness to information. With the information spread by those senders who have the same or the similar identity, lifestyle, etc. to receivers, consumers will think more valuable, So as to will be more positive attitude.

Situational factors in the process of word of mouth communication include availability of product/service and demand urgency. Availability of product/service will affect consumer attitudes. If 
purchasing of a product or service has a threshold limit or sales area restrictions, consumers who are subject to the relevant constraints would be more negative attitudes. Meanwhile, for consumers that have urgent needs, attitudes toward word of mouth will be more negative due to may not be concerned about information.

\section{Conclusions and recommendations}

Based on grounded theory, the paper analyzed the original data that obtained through personal depth interviews and focus group interviews with 55students from China University of Mining and Technology. The results show that ineffectiveness of positive word of mouth includes the relationship between senders and receivers, message factor, initial expectation, expectation gap, situational factor and psychological resistance. Moreover, message factor and consumer expectation have indirect impact on ineffectiveness of positive word-of-mouth that through psychological resistance, which formed the "message factor/expectation - psychological resistance -positive word of mouth ineffectiveness" driving relationship; the relationship between senders and receivers and situational factor play a regulatory role, which regulated the extent and intensity of "message factor - psychological resistance" and "psychological resistance -positive word of mouth ineffectiveness" relations. As the model of "message factor/expectation - psychological resistance -positive word of mouth ineffectiveness" is detectable based on grounded theory, the variables and their mechanism remains to be large sample quantitative validation.

Conclusion this study has certain guiding significance to the word of mouth marketing of enterprises. On the one hand, enterprises should pay attention to guiding the spread of consumer word of mouth. The more vivid of information, and the more concerned about content by consumers, the more positive attitudes can cause consumers to information. At the same time, if the information intensity will be bigger which enough to let the consumer remember, such the possibility of ineffectiveness of positive of word of mouth will get effectively reduced. In addition, the enterprise also should attach great importance to the influence of word order to consumer attitudes. If you hear negative information, it may cause consumers to have suspicious of product/service. At this time, if the company can timely provide an explanation, the situation will be eased. On the other hand, enterprises should make customer relationship management, in order to drive around potential consumers who have demand and have the ability to buy through spread of word of mouth from the existing.

\section{References}

[1] Arndt J.1967.Role of product-related conversations in the diffusion of a new product [J].Journal of Marketing Research, 291-295.

[2]Brown, Jacqueline J. and Peter H. Reingen.1987. Social ties and word-of-mouth referral behavior [J].Journal of Consumer Research, 14(3),350-362.

[3] Chevalier J A ,Mayztin D .2006.The effect of word of mouth oil sales: online book reviews[J].Journal of Marketing Research,43(3):345-354.

[4] De Bruyn, Arnaud and Gary L. Lilien.2008. A multi-stage model of word-of-mouth influence through viral marketing[J].International Journal of Research in Marketing,25(3),151-163.

[5] East, Robert, Kathy Hammond,and Wendy Lomax.2008.Measuring the impact of positive and 
negative word of mouth on brand purchase probability[J].International Journal of Research in Marketing,25(3),215-224.

[6] Froster.2012.http://www.pageaccess.com/500-ForresterUSInteractiveForecast_2009_2014.pdf.

[7] Feldman, Sidney and Merlin Spencer.1965. The effect of personal influence in the selection of consumer services [M]. In Marketing and Economic Development, Ed. Peter Bennett. Chicago: American Marketing Association.

[8] Gilly, M.C.,Graham,J.L., Wolfinbarger, M.F. and Yale, L.J.1998.A dyadic study of interpersonal information search [J]. Journal of the Academy of Marketing Science, 26(2):83-100.

[9] Huang Xiaojun, Xu Weiqing.2004. Reflections on the word of mouth communication research [J]. Journal of Zhejiang University (Humanities and Social Sciences), 34(1):125-132.

[10]LaBarbera,Priscilla A.and David Mazursky.1983.A longitudinal assessment of consumer satisfaction/dissatisfaction:the dynamic aspect of the cognitive process[J].Journal of Marketing Research,20(4),393-404.

[11] Li Dongjin, Jin Yuhua and Qin Yong.2005.Empirical study of the consumer instrumentality of WOM information source in China [J]. Chinese Journal of Management, 2(1):90-97.

[12] L Y.2006.Word of mouth for movies: its dynamics and impact on box office revenue [J].Journal of Marketing,70(3):74-89.

[13]Sen,Shahana and Fairleigh Dickinson.2008.Determinants of consumer trust of virtual word-of-mouth:an observation study from a retail website[J].Journal of American Academy of Business, 14(1):30-35.

[14] Sweeney, Jillian C., Geoffrey N. Soutar, and Tim Mazzarol .2008. Factors influencing word of mouth effectiveness: receiver perspectives[J].European Journal of Marketing, 42 (3/4):344-364.

[15] Strauss A, Corbin J.1994.Grounded theory approachology:an overview[M]//Denzin N K.Lincoln Y S(Eds.).Handbook of Qualitative Research.Thousand Oaks,CA.273-285. 